\title{
RESULTS OF EXPERIMENTAL DENSITY MANIPULATION IN AN ARIZONA LIZARD COMMUNITY ${ }^{1}$
}

\author{
DONALD W. TINKLE ${ }^{2}$ \\ Museum of Zoology and Division of Biological Sciences, The University of Michigan, \\ Ann Arbor, Michigan 48109 USA
}

\begin{abstract}
A study of three species of sceloporine lizards (Sceloporus clarki, S. undulatus, and Urosaurus ornatus) was begun in 1971 and continued into 1977 in a very diverse (at least 11 species) lizard community in central Arizona, USA. The present paper reports the results of a density manipulation experiment carried out with these three lizards to ascertain whether direct evidence for interspecific competition could be found in a community of lizards in which circumstantial evidence suggested its importance. In May 1975 the study area was divided along a natural constriction into an experimental area and a control area and an attempt was made to remove all $U$. ornatus and $S$. clarki from the experimental areas. This experimental treatment was maintained until the termination of the experiment in 1977. Patterns of habitat utilization, population density, survivorship, and individual body size of $S$. undulatus on experimental and control areas both before and after the removals were analyzed for evidence of competitive interactions. There was no detectable effect of the removal of $S$. clarki and $U$. ornatus on habitat selection, perch height, survivorship, population density, or individual body size of $S$. undulatus inhabiting the removal area. Implications of these results for studies of lizard community structure are discussed.
\end{abstract}

Key words: Arizona; competition; habitat selection; lizards; perturbation; Reptilia; Sceloporus; Urosaurus.

\section{INTRODUCTION}

A study begun in 1971 was continued into 1977 in a very diverse (at least 11 species) lizard community in central Arizona. Three of these species were studied in detail as part of a continuing effort to understand life history strategies of lizards. These three species were the tree lizard (Urosaurus ornatus), the eastern fence lizard (Sceloporus undulatus), and Clark's spiny lizard (Sceloporus clarki). Details of the life histories of these sympatric sceloporines are presented elsewhere (Tinkle 1981). The present paper reports the results of a density manipulation experiment carried out with these three lizards. The major objectives of this study were to ascertain whether direct evidence for interspecific competition could be found in a community of lizards in which circumstantial evidence suggested its importance, and to determine whether significant life history parameters such as survivorship, individual growth, and body size were affected by alterations in the competitive milieu.

Evidence for the importance of interspecific competition in structuring lizard communities is fairly convincing but largely circumstantial. This evidence includes apparent ecological character displacement in zones of overlap of closely related species, such as described in fossorial skinks in the Kalahari desert of Africa (Huey et al. 1974, Pianka et al. 1978). Habitat

\footnotetext{
1 Manuscript received 20 October 1980; revised 20 April 1981; accepted 27 April 1981.

${ }^{2}$ Deceased. Preparation of the manuscript for publication was completed by Arthur E. Dunham, Department of Biology, Joseph Leidy Laboratory of Biology, University of Pennsylvania, Philadelphia, Pennsylvania 19104 USA.
}

displacement or niche shift by species where they occur in sympatry with potential competitors has been documented in West Indian lizards of the genus Anolis (Schoener 1975). The pattern of body size variation among insular populations of the genus Uta in the Gulf of California has been interpreted as a result of competition with differing numbers of species of iguanid lizards (Soulé 1966). Although such comparative evidence as that for Uta is generally consistent with a competition hypothesis, it rarely allows us to choose among alternative hypotheses (Dunham et al. 1978). Strong et al. (1979) discussed the inherent weakness in the comparative approach to testing competition hypotheses. Schoener (1977) provided an excellent review of the various approaches to the study of competition in lizards.

Experimental studies of competition are much more difficult to carry out than comparative ones but have the potential for providing direct evidence of a competitive effect of one species (or many) on another, even though the mechanism by which competition is mediated may remain unclear (but see Dunham 1980). However, experimental studies also have some inherent weaknesses, some of which will be brought out in this study. First, they are almost necessarily short term, so the results might have little relevance to processes that operated historically in a community to bring about the present form and diversity of species. Second, field experimental studies may be very difficult to replicate, both because of habitat heterogeneity and logistic problems associated with intensive field studies. Third, due to temporal variation in the intensity of interspecific competition, short-term studies 
risk seriously underestimating the importance of competition over evolutionarily significant time periods.

In the lizard community chosen for study here, circumstantial evidence for the importance of competitive interactions among species was sufficiently strong to suggest the value of an experimental study. For example, some rare species in this community are widespread and numerically dominant elsewhere. Uta stansburiana is such a species; it is one of the most widespread and abundant lizards in most Lower and Upper Sonoran environments in the western United States, including areas not many miles from my study site. Nevertheless, only three individuals were marked during this study. Similarly, the desert spiny lizard (Sceloporus magister) was uncommon on the study area (23 marked during this study), but is abundant in other habitats near the study site. In both instances, a potential competitor or set of competitors common on the study area can be suggested as the possible cause of the rarity of these two generally common species. The pattern of habitat utilization also suggested competition. The eastern fence lizard (Sceloporus undulatus), one of the most abundant species in the community, is predominantly active on the ground, whereas two other species (Urosaurus ornatus and Sceloporus clarki) are highly arboreal. In southern Utah in habitat similar to that in Arizona, but in the absence of $U$. ornatus or $S$. clarki, $S$. undulatus was highly arboreal and found in the same trees with S. magister (Tinkle 1972). Finally, the area chosen for study contained an unusually diverse lizard community, suggesting the potential for competitive interactions among them, particularly in view of the fact that all are insectivores and several are of the same body size. In none of the plots used for sampling lizard species diversity in flatland deserts throughout much of the western United States did the number of species exceed 10 (Pianka 1967, 1978).

In the work I describe here I carried out experimental removal of species, expecting that if competition were important among the species chosen, such removals should result in one or more of the following effects on the species remaining: (1) altered pattern of habitat utilization; (2) altered pattern of resource use within the habitat; (3) increased density; (4) faster growth and, hence, larger body size; (5) enhanced survival; (6) increased clutch size or frequency.

\section{Materials AND Methods}

In 1971 I established a study area of 1.63 ha along a permanent stream in Upper Sonoran habitat in the Tonto National Forest near Sunflower, Maricopa County, Arizona at an elevation of $1077 \mathrm{~m}$. The stream bed and its associated riparian habitat contrasts sharply with the Upper Sonoran grassland-mesquite-juniper association in the surrounding areas.

The study area is elongate and borders a narrow stream which served as one boundary. Though the stream is only a few metres wide, the bed is about 70 $\mathrm{m}$ wide and consists of small stones and boulders in an essentially open habitat. No marked lizards are known to have crossed this barrier. The other boundary of the study plot was a steep talus slope with some abrupt rocky extrusions and cliffs. The study area itself was basically a woodland covered with several large species of trees (ash, cottonwood, and sycamore) and a number of generally smaller species such as willow, walnut, mesquite, juniper, and hackberry.

Of 11 species of lizards on the area, three $(U$. ornatus, $S$. undulatus, and $S$. clarki) were chosen for detailed population study. These three species span the size range for lizards in the community and all were relatively abundant. All species were studied from 1971-1975 without any density manipulation. The study area is nearly bisected at one point by a vertical rocky outcrop, and in the spring of 1975 the area east of this outcrop was designated as an experimental plot. The area to the west of it served as the control area. The two areas are unequal in size, the experimental area being $0.96 \mathrm{ha}$, the control $0.67 \mathrm{ha}$. Despite its smaller size, the control area has more trees but fewer large ones than the experimental area. Furthermore, trees make up less of the total area in the west area where boulders, rock outcrops and cliff faces, as well as fallen trees and brush, are more common. Thus the control area is structurally more diverse. At the beginning of the experiment, all three species were also near or at peak abundance recorded during the $6 \mathrm{yr}$ of this study. The removals of the very dense $U$. ornatus and $S$. clarki were expected to result in a rapid increase in numbers of $S$. undulatus. Removals of both $U$. ornatus and $S$. clarki were begun on the experimental area in May 1975 and repeated in August 1975, April 1976, and July 1976. No removals were conducted on the control area. No lizards were removed from either area in the last year (1977) of this study.

From 1971-1972 the study area was visited in every month. This provided a background against which to interpret the much shorter study intervals in other years, generally during early spring (April to May) or late summer (July to August). During the period 19711972 almost all attention was devoted to $U$. ornatus. During each period of the year that the areas were visited, each was worked daily, sometimes as many as four times, by at least three investigators. The study areas were traversed on foot and every rock, bush, and tree was carefully scrutinized. An attempt was made to continue working the areas until all lizards had been registered. The close correspondence between the numerous estimates of number and the actual census number during each study period indicated that this attempt was successful, although a few individuals escaped capture every year.

At initial capture each lizard was given a unique 
TABLE 1. Utilization of various perch types by each of three species of lizards on an Arizona study area before and after partial removal of $U$. ornatus and $S$. clarki in 1975-1976. Data prior to manipulations (Before) were collected from the whole study area in 1974 and in May 1975. Postmanipulation data are from August 1975 to May 1977. E = experimental area, $\mathrm{C}=$ control area.

\begin{tabular}{|c|c|c|c|c|c|c|c|c|c|}
\hline \multirow[b]{3}{*}{ Habitat } & \multicolumn{3}{|c|}{ Urosaurus ornatus } & \multicolumn{3}{|c|}{ Sceloporus clarki } & \multicolumn{3}{|c|}{ Sceloporus undulatus } \\
\hline & \multirow[b]{2}{*}{ Before } & \multicolumn{2}{|c|}{ After } & \multirow[b]{2}{*}{ Before } & \multicolumn{2}{|c|}{ After } & \multirow[b]{2}{*}{ Before } & \multicolumn{2}{|c|}{ After } \\
\hline & & $\mathrm{E}$ & $\mathrm{C}$ & & $\mathrm{E}$ & $\mathrm{C}$ & & $\mathbf{E}$ & $\mathrm{C}$ \\
\hline \multicolumn{10}{|c|}{ Large trees } \\
\hline $\begin{array}{l}N \\
\%\end{array}$ & $\begin{array}{l}130 \\
33.4\end{array}$ & $\begin{array}{l}20 \\
32.3\end{array}$ & $\begin{array}{l}51 \\
19.8\end{array}$ & $\begin{array}{l}46 \\
38.3\end{array}$ & $\begin{array}{c}8 \\
40.0\end{array}$ & $\begin{array}{l}11 \\
35.5\end{array}$ & $\begin{array}{l}25 \\
18.7\end{array}$ & $\begin{array}{l}11 \\
14.9\end{array}$ & $\begin{array}{l}4 \\
7.1\end{array}$ \\
\hline \multicolumn{10}{|c|}{ Small trees } \\
\hline $\begin{array}{l}N \\
\%\end{array}$ & $\begin{array}{l}107 \\
27.5\end{array}$ & $\begin{array}{l}16 \\
25.8\end{array}$ & $\begin{array}{l}69 \\
26.8\end{array}$ & $\begin{array}{l}57 \\
47.5\end{array}$ & $\begin{array}{c}8 \\
40.0\end{array}$ & $\begin{array}{l}11 \\
35.5\end{array}$ & $\begin{array}{l}25 \\
18.7\end{array}$ & $\begin{array}{l}13 \\
17.6\end{array}$ & $\begin{array}{c}9 \\
16.1\end{array}$ \\
\hline $\begin{array}{l}\text { Fallen tre } \\
\qquad \\
\%\end{array}$ & $\begin{array}{l}82 \\
21.1\end{array}$ & $\begin{array}{l}16 \\
25.8\end{array}$ & $\begin{array}{l}58 \\
22.6\end{array}$ & $\begin{array}{l}8 \\
6.7\end{array}$ & $\begin{array}{l}1 \\
5.0\end{array}$ & $\begin{array}{l}2 \\
6.5\end{array}$ & $\begin{array}{l}12 \\
9.0\end{array}$ & $\begin{array}{l}5 \\
6.8\end{array}$ & $\begin{array}{c}7 \\
12.5\end{array}$ \\
\hline \multicolumn{10}{|c|}{ Boulders and rockface } \\
\hline $\begin{array}{l}N \\
\%\end{array}$ & $\begin{array}{l}61 \\
15.7\end{array}$ & $\stackrel{9}{14.5}$ & $\begin{array}{l}73 \\
28.4\end{array}$ & $\begin{array}{l}8 \\
6.7\end{array}$ & $\begin{array}{c}2 \\
10.0\end{array}$ & $\begin{array}{c}6 \\
19.4\end{array}$ & $\begin{array}{l}20 \\
14.9\end{array}$ & $\begin{array}{l}15 \\
20.3\end{array}$ & $\begin{array}{l}19 \\
33.9\end{array}$ \\
\hline \multicolumn{10}{|l|}{ Ground } \\
\hline $\begin{array}{l}N \\
\%\end{array}$ & $\begin{array}{l}9 \\
2.3\end{array}$ & $\begin{array}{l}1 \\
1.6\end{array}$ & $\begin{array}{l}6 \\
2.3\end{array}$ & $\begin{array}{l}1 \\
0.8\end{array}$ & $\begin{array}{l}1 \\
5.0\end{array}$ & $\begin{array}{l}1 \\
3.2\end{array}$ & $\begin{array}{l}52 \\
38.8\end{array}$ & $\begin{array}{l}30 \\
40.5\end{array}$ & $\begin{array}{l}17 \\
30.4\end{array}$ \\
\hline Total & 389 & 62 & 257 & 120 & 20 & 31 & 134 & 74 & 56 \\
\hline
\end{tabular}

identifying number and corresponding toe clip (Tinkle 1967). At each capture, snout-vent length (SVL) was measured to the nearest millimetre and each lizard was given a small paint dot over the hind limb insertions to avoid repeated capture and to facilitate counts of previously marked individuals for calculations of Lincoln-Petersen estimates of population density (Seber 1973). The mark-recapture study provided data on growth, age at maturity, population density, survivorship, and habitat utilization. During the last $3 \mathrm{yr}$ of the study, data were collected on the exact location of each animal in the habitat at each capture. These data provided information on differences in habitat use before and after the experimental removals.

During this study, a total of $209 \mathrm{~S}$. undulatus, 153 $S$. clarki, and $882 U$. ornatus were registered on the study area. The immediate margins of the area were checked each time the study area was traversed. We occasionally searched adjacent areas a considerable distance from the study area boundaries to look for emigrants. Few lizards were found far outside the study area, presumably because the habitat of the study area was much more favorable than that beyond the riparian zone.

\section{Results}

\section{Habitat utilization}

I expected the most dramatic experimental effects on habitat utilization. As noted earlier, $S$. undulatus was highly arboreal on my area in southern Utah (Tinkle 1972) and also uses the trees to a considerable degree on the Arizona area. Because both $U$. ornatus and $S$. clarki are predominantly arboreal, I expected their removal to result in a marked shift by $S$. undulatus to more arboreal habits. Data were collected on habitat utilization in 1974 and May 1975 during the first removals. Postmanipulation data are from August 1975 to May 1977 (Table 1).

The data collected prior to density reductions of $U$. ornatus and $S$. clarki show clearly the habitat differences among the three species. About $60 \%$ of the captures of $U$. ornatus were in small or large trees, and only $2 \%$ of the captures were on the ground. Similarly, $85 \%$ of the captures of $S$. clarki were in trees and only $1 \%$ on the ground. In contrast, $\approx 39 \%$ of the captures of $S$. undulatus were on the ground and only $\approx 37 \%$ in trees.

The data collected after removal (Table 1) suggest some increase in utilization of trees by $S$. undulatus on the experimental area relative to control. Thus, $32.4 \%$ of the captures on the experimental area from which $S$. clarki and $U$. ornatus were removed were in trees, compared with $23.2 \%$ on the control area. However, this difference is not significant $\left(\chi^{2}{ }_{1}=1.33\right.$, $P>.2$ ). In addition, the fact that the utilization of trees by $S$. undulatus after removals began (32.4\%) did not differ significantly $\left(\chi^{2}{ }_{1}=0.50, P>.4\right)$ from that prior to manipulation (37.3\%) led me to reexamine the data from the experimental and control areas in May 1975, the beginning of the experimental period. At that time, $52.2 \%$ of the captures of $S$. undulatus on the experimental area were in trees compared with $33.3 \%$ on the control area. Therefore, no evidence exists that $S$. undulatus increased its utili- 
TABLE 2. Recorded perch heights of individuals of three species of lizards on an Arizona study area before and after partial removal of $U$. ornatus and $S$. clarki. Percentage use of each perch height category in parentheses. See Table 1 for other details.

\begin{tabular}{|c|c|c|c|}
\hline \multirow[b]{2}{*}{ Species and area } & \multicolumn{3}{|c|}{ Number (percentage) of individual } \\
\hline & $\begin{array}{l}\text { Perch height } \\
<1 \mathrm{~m}\end{array}$ & $\begin{array}{l}\text { Perch height } \\
>1 \mathrm{~m}\end{array}$ & Total \\
\hline \multicolumn{4}{|c|}{ Sceloporus undulatus } \\
\hline \multicolumn{4}{|c|}{ Experimental area } \\
\hline Before & $13(61.9)$ & $8(38.1)$ & 21 \\
\hline After & $43(65.2)$ & $23(34.8)$ & 66 \\
\hline \multicolumn{4}{|l|}{ Control area } \\
\hline Before & $23(69.7)$ & $10(30.3)$ & 33 \\
\hline After & $40(67.8)$ & $19(32.2)$ & 59 \\
\hline \multicolumn{4}{|c|}{ Urosaurus ornatus } \\
\hline \multicolumn{4}{|c|}{ Experimental area } \\
\hline Before & $31(45.6)$ & $37(54.4)$ & 68 \\
\hline After & $15(23.8)$ & $48(76.2)$ & 63 \\
\hline \multicolumn{4}{|l|}{ Control area } \\
\hline Before & $60(38.5)$ & $96(61.5)$ & 156 \\
\hline After & $77(30.9)$ & $172(69.1)$ & 249 \\
\hline \multicolumn{4}{|c|}{ Sceloporus clarki } \\
\hline \multicolumn{4}{|c|}{ Experimental area } \\
\hline Before & $6(40.0)$ & $9(60.0)$ & 15 \\
\hline After & $1(6.7)$ & $14(93.3)$ & 15 \\
\hline \multicolumn{4}{|l|}{ Control area } \\
\hline Before & $4(19.0)$ & $17(81.0)$ & 21 \\
\hline After & $6(18.2)$ & $27(81.8)$ & 33 \\
\hline
\end{tabular}

zation of trees after removal of potential arboreal competitors. Furthermore, the data (Table 1) indicate that $U$. ornatus was also more arboreal $\left(\chi^{2}{ }_{1}=2.59, P>\right.$ .1) on the experimental (58\%) area than on the control (47\%) after the removal experiments. The data in Table 1 suggest that $S$. clarki also tended to increase its proportional use of trees on the experimental area $(80 \%)$ relative to the control area $(71 \%)$ following the removal experiment; however, this difference is not significant $\left(\chi^{2}{ }_{1}=.52, P>.4\right)$. As in $S$. undulatus, the difference in utilization of trees between experimental and control areas existed prior to density manipulation and probably simply reflects the fact that proportionately more of the total habitat of the experimental area consisted of trees.

Because so much of the habitat is vertical, I also analyzed perch height (Table 2). There was no significant difference $\left(\chi^{2}{ }_{1}=.098, P>.7\right)$ between the proportion of perches used by $S$. undulatus that were below $1 \mathrm{~m}$ on the experimental area (.65) and the control area (.68) after removal of $S$. clarki and $U$. ornatus. Likewise, comparison of perch heights used by $S$. undulatus on the two areas before and after removal revealed no significant differences $\left(\chi^{2}{ }_{1}\right.$ tests all $P>$.1). Thus, $S$. undulatus showed no significant alteration in perch height that can be attributed to removal of potential competitors. After the removals,
$U$. ornatus on the experimental area increased its use of perches $>1 \mathrm{~m}\left(\chi^{2}{ }_{1}=6.81, P<.05\right)$. This change could result from reduced intraspecific competition from other Urosaurus allowing more of the remaining individuals to use high areas of the trees, or it could be due to the reduction in numbers of $S$. clarki which, because of their large size, are potential predators on $U$. ornatus; a $U$. ornatus was found in the stomach of an $S$. clarki autopsied during this study. $S$. clarki increased $\left(\chi^{2}{ }_{1}=4.66, P<.05\right)$ its proportional use of perches $>1 \mathrm{~m}$ on the experimental area from .60 to .93. However, the sample sizes used in this test are small and this result must, therefore, be viewed with suspicion. If this result is not spurious, it probably reflects active selection of preferred habitat by individuals under conditions of reduced density of conspecifics.

In summary, there are clear differences in habitat utilization among the three species. Because of habitat heterogeneity, there are differences between the two study areas in habitat utilization. However, none of the experimental results suggests unequivocally that Sceloporus undulatus increased either its use of trees or the height of its foraging in trees as a result of the removal of the more arboreal species with which it coexists.

\section{Density}

The density of lizards for all time periods in which accurate census or Lincoln-Petersen index estimates were available shows considerable variability among years in all three species (Table 3). During the $3 \mathrm{yr}$ prior to the first removal experiment in May 1975, density of $U$. ornatus varied from $80-171 /$ ha (Tinkle 1981). Density in this species is always at a peak in late fall and early spring because of annual recruitment and then declines substantially during the summer. However, even among the summers of 1972-1974, numbers of $U$. ornatus lizards varied by a factor of two (Tinkle 1981). This degree of variation also occurred in $S$. clarki, but numbers of $S$. undulatus were relatively stable (Tinkle 1981). These data on variation in number prior to manipulation are an important baseline against which to judge the effects of the manipulations.

At the beginning of the experimental removals in May 1975, all three species were more dense on the control area than on the experimental, and this difference between areas presumably existed in earlier years as well. In May of 1975, 71 U. ornatus were removed from the experimental area. Only 11 additional individuals were found and removed when the census was repeated in August. An additional 28 were removed in April and 4 more in July of 1976. The number removed in May represents $100 \%$ of the lizards estimated to have been present at that time (Table 3). The numbers of $S$. clarki removed were 16 in May 1975, 9 in August of 1975, none in April, and two in 
TABLE 3. Numbers and density (lizards/ha) for each species in the study area. Density estimates are in parentheses and are based on direct census or on Lincoln-Peterson estimates (Seber 1973), whichever provided the larger estimate for the time period. $* * *$ indicates no data.

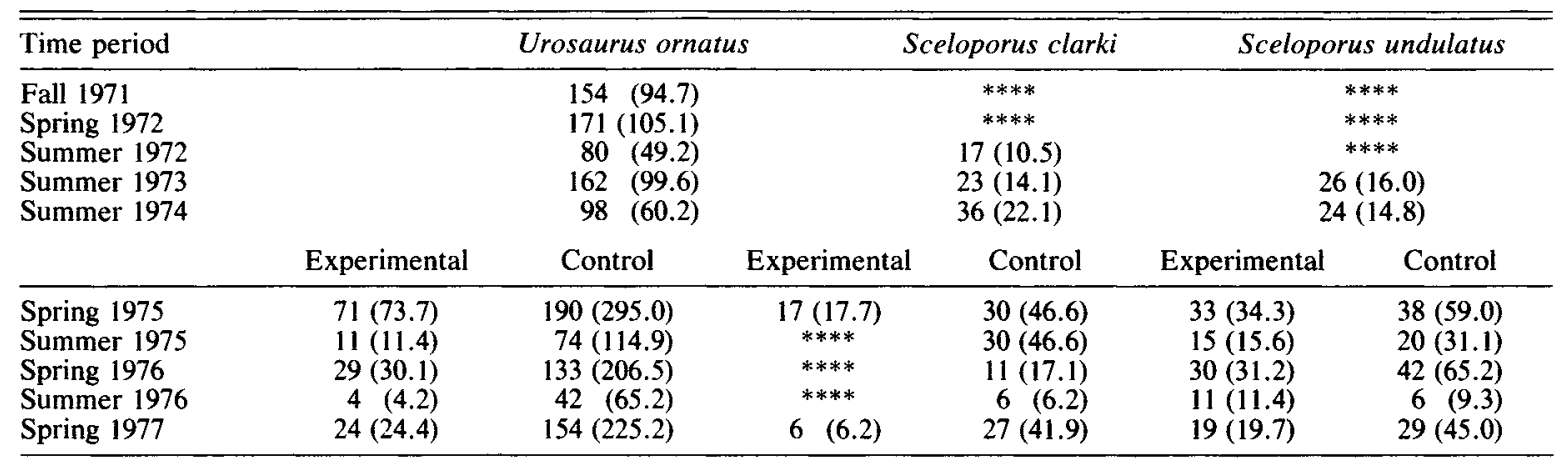

July of 1976 . Thus, the 1975 removals essentially eliminated $S$. clarki from the experimental area, along with about three-fourths of the Urosaurus. The $U$. ornatus removed in the spring of 1976 were almost all yearlings born the previous summer, and so could represent eggs laid by females which were missed in the first removal census in May 1975.

Immediately following the May removals, the numbers of $S$. undulatus on the experimental area declined from 33 to $15 /$ ha $(55 \%)$ while the density on the control area declined by $47 \%$ (Table 3). From August 1975 to spring 1976 , the numbers of $S$. undulatus essentially doubled on both experimental and control areas. The decline during the season in 1976 was by $64 \%$ on the experimental area, but it rebounded by $73 \%$ between 1976 and 1977, while numbers on the control area increased by $350 \%$ ! These data certainly provide no evidence for an increase in density of $S$. undulatus attributable to the removal of potential competitors. In fact, at the conclusion of this study in 1977 the densities of Urosaurus on both experimental and control areas were still lower than at the beginning of the experiment. This was also true of $S$. clarki on the experimental area, though the numbers on the control area were near those at the beginning of the experiment. However, almost all of these $S$. clarki were small yearlings. Thus the numbers of potential competitors remained low for $2 \mathrm{yr}$.

It is of interest to compare the change in numbers on the experimental plot by $S$. undulatus with parallel changes of the other two species on the control plot. Thus, $S$. clarki during 1975 did not decline in density, but Urosaurus declined by $61 \%$ and $S$. undulatus by 47\%. S. clarki did decline markedly between 1975 and 1976, while $S$. undulatus rebounded in the spring of that year and declined abruptly over the summer. All three species declined in 1976: $U$. ornatus by $68 \%, S$. clarki by $45 \%$, and $S$. undulatus by $86 \%$. By the end of the study, Urosaurus had returned to $76 \%$ of its original density on the control area and $S$. clarki had returned to $90 \%$. On the experimental area where $S$. undulatus had occurred for $2 \mathrm{yr}$ in the virtual absence of potential competitors, its numbers were still only $58 \%$ of that at the start of the experiment.

Thus, data on population densities, like those on habitat utilization, provide no convincing evidence of a competitive effect of $S$. clarki and $U$. ornatus on $S$. undulatus.

\section{Survivorship}

Interspecific competition should result in reduced survivorship of the species most affected regardless of whether the competition is of an exploitative or interference nature. However, the data on survivorship also provide no evidence for a significant competitive effect (Table 4).

There were no significant differences in the survivorship of $S$. undulatus on the experimental and control areas from the summer of 1975 to the spring of $1976\left(\chi^{2}{ }_{1}=.10, P>.7\right)$, or from the summer of 1976 to the spring of $1977\left(\chi^{2}{ }_{1}=.23, P>.6\right)$. Likewise, there were no significant differences in the spring-summer $(\approx 3 \mathrm{mo}$ ) survivorship of $S$. undulatus on the experimental and control areas in either $1975\left(\chi^{2}{ }_{1}=.01\right.$, $P>.8)$ or $1976\left(\chi_{1}^{2}=.75, P>.3\right)$. Although these data provide no compelling evidence of competitive interaction between $S$. undulatus and the removed species, they do demonstrate a large amount of variation among years in both the spring-summer $(\approx 3 \mathrm{mo})$ and summer-spring $(\approx 9 \mathrm{mo})$ survivorships of $S$. undulatus. For example, the summer-spring survivorship of $S$. undulatus from 1976-1977 was higher than recorded for any previous time period. The survivorship of $U$. ornatus and $S$. clarki on the control area was also analyzed, but provided little of interest because no comparative data were available from the experimental area, from which these species were removed. However, the survivorship of Urosaurus on the control area was extraordinarily high from 1975-1976 (73.5\%) and 1976-1977 (48.1\%), suggesting that the 2 yr were unusually favorable. Sample sizes of $S$. clarki were too small to allow definitive conclusions. 
TABLE 4. Survivorship of marked lizards before and after partial removal of $U$. ornatus and $S$. clarki. Survivorship for the removed species was calculated for the control area only. Figures show number marked and percentage survival over each time interval.

\begin{tabular}{|c|c|c|c|c|c|c|}
\hline \multirow[b]{2}{*}{ Survivorship interval } & \multicolumn{6}{|c|}{ Number originally marked and percent surviving } \\
\hline & \multicolumn{2}{|c|}{ Sceloporus undulatus } & \multicolumn{2}{|c|}{ Urosaurus ornatus } & \multicolumn{2}{|c|}{ Sceloporus clarki } \\
\hline \multicolumn{7}{|l|}{ Summer-summer } \\
\hline $\begin{array}{c}\text { Before } 1975 \\
(1972-73 \\
1973-74)\end{array}$ & \multicolumn{2}{|c|}{$\begin{array}{c}49 \\
20 ; 21 \% \\
\bar{x}=20.5 \%\end{array}$} & \multicolumn{2}{|c|}{$\begin{array}{c}332 \\
16.1 ; 32.3 \% \\
\bar{x}=24.2 \%\end{array}$} & \multicolumn{2}{|c|}{$\begin{array}{c}55 \\
34.6 ; 41.4 \% \\
\bar{x}=38.0 \%\end{array}$} \\
\hline \multicolumn{7}{|l|}{ Summer-spring } \\
\hline $\begin{array}{c}\text { Before } 1975 \\
(1974-75)\end{array}$ & \multicolumn{2}{|c|}{$\begin{array}{c}33 \\
42.4 \%\end{array}$} & \multicolumn{2}{|c|}{$\begin{array}{c}139 \\
33.8 \%\end{array}$} & \multicolumn{2}{|c|}{$\begin{array}{c}46 \\
32.6 \%\end{array}$} \\
\hline $\begin{array}{l}\text { After } 1975 \\
\quad(1975-76)\end{array}$ & $\begin{array}{c}E \\
12 \\
25.0 \%\end{array}$ & $\begin{array}{c}C \\
13 \\
30.8 \%\end{array}$ & $\begin{array}{c}\mathbf{E} \\
\cdots\end{array}$ & $\begin{array}{c}C \\
49 \\
73.5 \%\end{array}$ & $\begin{array}{l}\mathrm{E} \\
\cdots\end{array}$ & $\begin{array}{c}\mathrm{C} \\
14 \\
35.7 \%\end{array}$ \\
\hline$(1976-77)$ & $\begin{array}{c}11 \\
63.6 \%\end{array}$ & $\begin{array}{c}4 \\
50.0 \%\end{array}$ & & $\begin{array}{c}27 \\
48.1 \%\end{array}$ & & $\begin{array}{c}4 \\
50.0 \%\end{array}$ \\
\hline \multicolumn{7}{|l|}{ Spring-summer } \\
\hline $\begin{array}{l}\text { Before } 1975 \\
(1972)\end{array}$ & \multicolumn{2}{|c|}{$\begin{array}{c}12 \\
63.6 \%\end{array}$} & \multicolumn{2}{|c|}{$\begin{array}{c}198 \\
40.1 \%\end{array}$} & \multicolumn{2}{|c|}{$\begin{array}{c}15 \\
26.7 \%\end{array}$} \\
\hline $\begin{array}{l}\text { After } 1975 \\
(1975)\end{array}$ & $\begin{array}{c}\mathrm{E} \\
25 \\
36.0 \%\end{array}$ & $\begin{array}{c}\mathrm{C} \\
24 \\
37.5 \%\end{array}$ & $\begin{array}{c}\mathrm{E} \\
\cdots\end{array}$ & $\begin{array}{c}\mathrm{C} \\
122 \\
25.4 \%\end{array}$ & $\begin{array}{c}\mathbf{E} \\
\cdots\end{array}$ & $\begin{array}{c}C \\
15 \\
40.0 \%\end{array}$ \\
\hline (1976) & $\begin{array}{c}29 \\
27.6 \%\end{array}$ & $\begin{array}{c}23 \\
17.4 \%\end{array}$ & $\cdots$ & $\begin{array}{c}92 \\
26.1 \%\end{array}$ & $\cdots$ & $\begin{array}{c}7 \\
57.1 \%\end{array}$ \\
\hline
\end{tabular}

\section{Body size and mass}

Body sizes are difficult to compare among years, but any differences in body sizes of $S$. undulatus between the experimental and control area in the same year would be of great interest, particularly if it could be demonstrated that these size differences are different from those existing on the two areas when manipulations began.

However, there was remarkable agreement in SVL of lizards on experimental and control areas for every time period considered (Table 5). Furthermore, the minor differences in mean size that do exist are not in the direction of larger size on the experimental area, as would be expected if they were due to release from competition. Finally, there is no tendency for the average size of $S$. undulatus on the experimental area to increase with time from the premanipulative size observed in May 1975 to that in 1977, despite the reduction in densities of $U$. ornatus and $S$. clarki over that time period.

Body mass may provide different information than body length by revealing the relative fatness of animals. Under a competitive hypothesis, size-specific body mass of $S$. undulatus on the experimental area ought to be greater than for those lizards on the control area. Data on body masses were available only for May 1977, at the termination of the study. One-way analaysis of covariance on logarithmically transformed variables revealed no significant difference in the regressions of body mass on SVL for $S$. undulatus on the experimental and control areas (Fig. 1). The greater number of very large lizards on the experimental area relative to the control probably reflects the high survivorship on the experimental area from 19761977.

\section{Discussion}

The results of this study suggest that the habitat occupied by $S$. undulatus on my study area is not a result of current competitive interactions with the two species removed from the experimental area. Sceloporus undulatus did not increase its use of arboreal habitats after removal of highly arboreal potential competitors. This result seems especially significant in view of the high degree of arboreality of $S$. undulatus in other similar habitats where it has been studied (Tinkle 1972). The data also do not suggest a change in perch height following removal of competitors.

One may argue that a past history of competitive interactions among these species has resulted in a genetically based avoidance of habitats utilized by competitors. Rosenzweig (1979) has provided a theory of "trade-off habitat selection" which predicts precisely this result. There is evidence from several perturbation studies of small-mammal communities (e.g., Schroder and Rosenzweig 1975, and Abramsky et al. 1979) which suggest that a lack of habitat shift following removal of a competitor, such as obtained in this study, may be quite general and a predictable result of the evolution of habitat selection. However, be- 
TABle 5. Mean snout-vent length (mm) of Sceloporus undulatus on experimental and control areas during and following partial removal of Sceloporus clarki and Urosaurus ornatus. Sizes of yearling and older lizards are shown separately for those time periods when these two classes are separable on the basis of size. Sexes were lumped, in absence of major size differences, in order to increase sample size. Sample sizes are in parentheses.

\begin{tabular}{|c|c|c|c|}
\hline \multirow[b]{2}{*}{ Time period } & \multirow[b]{2}{*}{ Age class } & \multicolumn{2}{|c|}{ Snout-vent length ( $\mathrm{mm}$} \\
\hline & & $\begin{array}{l}\text { Experimen- } \\
\text { tal area }\end{array}$ & $\begin{array}{l}\text { Control } \\
\text { area }\end{array}$ \\
\hline May 1975 & $\begin{array}{l}\text { yearling } \\
\text { older }\end{array}$ & $\begin{array}{l}47.5(15) \\
63.6(11)\end{array}$ & $\begin{array}{l}50.1(15) \\
63.6(9)\end{array}$ \\
\hline August 1975 & all except hatchlings & $62.5(13)$ & $62.3(12)$ \\
\hline April 1976 & $\begin{array}{l}\text { yearling } \\
\text { older }\end{array}$ & $\begin{array}{l}49.1(21) \\
64.3(3)\end{array}$ & $\begin{array}{l}49.4(16) \\
62.2(7)\end{array}$ \\
\hline July 1976 & all except hatchlings & $58.3(12)$ & $58.4 \quad(7)$ \\
\hline May 1977 & $\begin{array}{l}\text { yearling } \\
\text { older }\end{array}$ & $\begin{array}{l}48.3(8) \\
64.4(10)\end{array}$ & $\begin{array}{l}51.3(12) \\
64.2(6)\end{array}$ \\
\hline
\end{tabular}

cause competition must surely be stronger among conspecific than heterospecific individuals, it seems likely that intraspecific competition would result in retention of a labile habitat-choice mechanism that would allow rapid expansion into unused habitat, in this case habitat from which interspecific competitors had been removed. There can be little doubt that increases and decreases in intraspecific competition in lizards can result in some fairly dramatic short-term changes. For example, direct addition of localized resources has been shown to alter the size of territories defended by Sceloporus jarrovi in a time span of $<2$ wk (Simon 1975). Likewise, Licht (1974) showed that Anolis lizards displayed significant increases in body mass after artificial food supplementation in nature, and that they quickly responded behaviorally to incremented resources in their immediate environment. Turner et al. (1974) carried out several field enclosure studies with the lizard Uta stansburiana that revealed dramatic effects of increased precipitation or artificial irrigation on the frequency of clutch production. Manipulation of density, too, had demonstrable negative effects on adult survival, though not on reproduction. In the present study, the possibility cannot be ruled out that other factors (e.g., predation) may have acted to keep the population density sufficiently low that the level of intraspecific competition on the removal area was never sufficient to result in habitat expansion. The diversity data suggest this. Increased predation on $S$. undulatus from generalized lizard predators following the removal of $U$. ornatus and $S$. clarki may have prevented the density of $S$. undulatus on the experimental area from increasing and at the same time prevented any increase in the survival of resident $S$. undulatus.

Body size and condition, as measured by size-specific mass, were also not different in this study be-

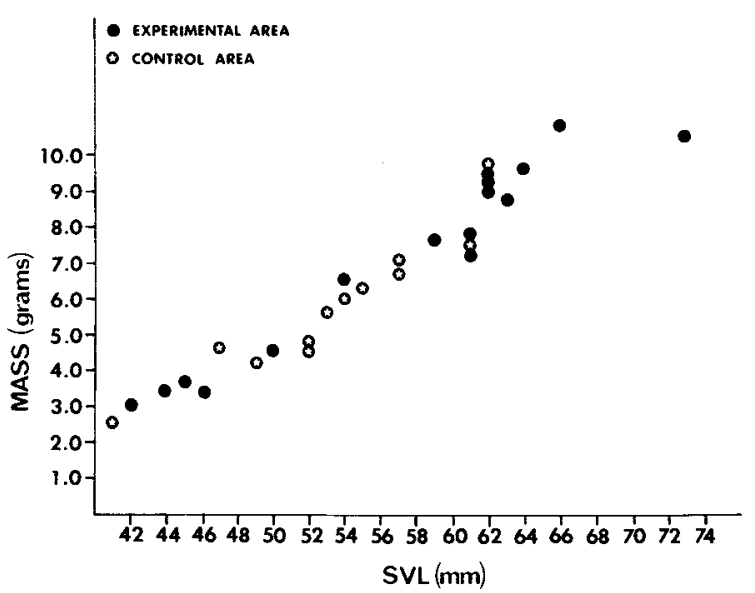

FIG. 1. Regression of body mass on body length (as snout-vent length) of Sceloporus undulatus on an Arizona study area in May 1977.

tween animals from the experimental or the control area. With the removal of potential competitors, I expected that $S$. undulatus on the experimental area, without incurring additional risk, should have had increased resources available. Given the obvious advantages of larger body size for reproduction and presumably for survival, these increased resources were expected to go into growth in younger lizards or into greater fat storage and therefore body mass in fully grown individuals. However, neither of these results was observed; there were no differences between lizards from the experimental and control areas.

This leaves only survivorship and density, among those variables that I measured, on which to base an interpretation of competitive interaction in this lizard assemblage. The removal of $U$. ornatus and $S$. clarki was exceedingly effective in the spring of 1975 , allowing 2 full $y r$ for the manifestation of effects of the removal on the density or survivorship of $S$. undulatus before termination of the study in 1977. However, there were no significant changes in the density of $S$. undulatus that could be attributed to the removal of competitors. The density of $S$. undulatus on the experimental area after the removals, was not greater than on the control area nor compared to its overall density prior to the experiments. However, the densities on both experimental and control areas seemed more variable after than prior to the experiments.

Survivorship also provided no evidence for a significant competitive effect. Observed differences in survivorship were not accompanied by differences in density and were not statistically significant. In two comparisons, differences in survivorship were in the direction predicted by a competitive hypothesis, but a change of survivorship in the absence of a change in density seems trivial as an outcome of competition and led me to examine the survivorship data more closely. As noted, the major change in survivorship of 
S. undulatus was on the experimental area from spring to summer of 1976; survivorship from 1976 to 1977 was also high, but not significantly different from that on the control area. Thus density on the experimental area should have increased in 1977 relative to the control. In contrast, the actual numbers of individuals on the two areas in 1977 were identical, so density on the much smaller west area was higher than on the east and showed a greater proportional increase over 1976 than was observed on the experimental area.

Differences in survivorship on the experimental area resulted in differences in age structure between the two areas. On the experimental area in 1977, over onehalf the lizards registered were 2 or more yr of age compared with only one-third on the control; the remainder in both cases were young of the previous year. Perhaps this difference in age structure was sufficient to cause a difference in survivorship of younger (i.e., hatchlings from 1976) lizards. That is, intraspecific interactions between older and younger lizards would, if important, have been more frequent on the experimental area than on the control and could have resulted in higher emigration from that area than from the control, thereby masking the expected density change.

The fact remains, however, that in spite of a dramatic change in the species milieu wrought by the experimental removals, only a rather small, statistically insignificant, and ephemeral change in survivorship resulted. Pianka (1967) pointed out that the environments of the Mojave and Sonoran deserts were the most variable in the southwestern United States. My study area borders the Sonoran desert, and was quite variable in rainfall, which is known to be closely correlated with productivity (Ballinger 1977, Dunham 1980). For example, spring rainfall over the years of this study varied from 0 to $226 \mathrm{~mm}$ (Tinkle 1981). Early summer rainfall varied by a factor of 5 and late summer rain by an order of magnitude. Inasmuch as the three lizard species studied here do not respond identically in the same year, it is likely that whereas one species enjoys outstanding success in reproduction and survival in some years, another species might do best in other years. These patterns of variability could result in long-term fluctuations in numbers that may be of greater importance than are competitive interactions in determining relative abundances of these species. Such fluctuations, however, should occasionally result in an alteration of diversity due to local extinctions. Indeed, at least two such extinctions were observed in this study. Both species of whiptail lizard (Cnemidophorus tigris and C. fagellicaudus) were abundant on the area through 1974, but have not been seen on the area since 1975. Periodic investigations of nearby areas in the same habitat indicated that the extinctions were not limited to the study area. Milstead (1965) documented striking changes in the numerical relationships among three species of whiptail lizard in western Texas between 1952 and 1962 and suggested that a gradual trend toward more mesic conditions resulted in one of the three formerly equally abundant species becoming predominant while the others became rare. Even among species upon which this study was focused, there were some dramatic changes. For example, both $U$. ornatus and $S$. clarki reached exceedingly low densities on the study area in 1976, as well as in areas nearby. In both species, these densities were less than one-quarter what they had been only a year earlier.

Experimental studies of interspecific competition in lizard communities have been rare. In contrast, comparative studies of factors such as resource allocations and niche overlap and of apparent ecological character displacement abound. In addition to the experimental work reported here, there are only three other published experimental field studies of lizard competition. Two carefully replicated field studies have been carried out by Dunham (1980) and Smith (1977). Smith conducted replicated removal experiments in southern Arizona on an area on which $U$. ornatus and Sceloporus virgatus were abundant and utilized similar food resources. The removal of Urosaurus was accompanied by an increase in individual growth rates of $S$. virgatus, but only that of yearling females and only in the year following the removals, a year that was marked by low resource levels and probably unusually strong competition. Similarly, Dunham (1980) carried out reciprocal removal experiments in a two-species lizard guild in southwestern Texas consisting of the saxicolous species $U$. ornatus and Sceloporus merria$m i$. The removal of $U$. ornatus had no detectable effects on $S$. merriami, but removal of $S$. merriami was followed by higher densities, individual growth rates, size-specific body masses, and stored lipid levels in Urosaurus. However, these competitive effects were sometimes small, ephemeral, and limited to years in which measured resource levels in the environment were low. Furthermore, some variables, such as adult survival, behaved in a manner unpredictable from a competition hypothesis, for they decreased on the experimental plots. Finally, Radovanovic (from discussion in Nevo et al. 1972) studied two species of $L a-$ certa that have mutually exclusive distributions on most small islands in the Adriatic, a pattern suggesting a history of competitive interactions between these species. He introduced one or the other species onto four islands where only one of the species was previously known. Nevo et al. (1972) followed up this experiment by revisiting three islands. On only one had the introduction succeeded. The results of this study, however, can certainly be interpreted in ways that require no interspecific competitive interactions.

In summary, experimental studies of competition in lizard communities have failed to implicate interspecific competition as a decisive factor in the regulation of numbers or of diversity. Environmental variability 
has frequently confounded the results of experiments. Replication would allow statistical control of the effects of this variability, but could make most field experiments impossible. Clearly needed are more experimental studies, particularly in insular communities such as those of the West Indies that have furnished so much of the circumstantial evidence for competition.

Despite the inconclusive nature of field experiments thus far, they remain the best hope for establishing a causative relationship between competitive interactions and the circumstantial evidence for the evolutionary significance of the effects of these presumed interactions that has been provided by numerous comparative studies (Schoener 1977, for review). I suggest that long-term experimental field studies in which numbers of predators are carefully monitored, and if possible manipulated, will be particularly instructive.

\section{ACKNOWLEDGMENTS}

Almost all of the field work on which this report is based was carried out by me with the assistance, principally, of my two sons Randall and Steven, to whom I am particularly grateful. I'm also particularly grateful to Justin Congdon who made a major contribution to the field effort in several years. James Collins and Phil Rosen each helped me extensively during one field season. The following individuals provided me with occasional and much appreciated assistance: Melanie Tinkle, Richard van LobenSels, Nancy Dickson, Laurie Vitt, Michael and Jody Minzell, James Platz, Art Hulse, Jenny Hackforth-Jones, Neil Hadley, George Constantz, and William Milstead. I'm also grateful to Laurie Vitt for providing me with some unpublished data on Urosaurus body sizes and to Art Dunham for furnishing rainfall records from the weather station near my study area and for critical comments on an early draft of this paper. This work was supported by grants GB 8706 and GB 29141 from the National Science Foundation.

Addendum: This paper is based on a partially completed manuscript left behind by Professor Tinkle and completed by me. Drs. J. Whitfield Gibbons, Justin D. Congdon, and Laurie J. Vitt read various drafts of this paper and aided in its completion. Sandy Bowne and Karen Overall aided greatly in the preparation of the manuscript.-Arthur E. Dunham.

\section{Literature Cited}

Abramsky, Z., M. I. Dyer, and P. D. Harrison. 1979. Competition among small mammals in experimentally perturbed areas of the shortgrass prairie. Ecology 60:530-536.

Andrews, R. S. 1979. Evolution of life histories: a comparison of Anolis lizards from matched island and mainland habitats. Breviora 454:1-57.

Ballinger, R. E. 1977. Reproductive strategies: food availability as a source of proximal variation in a lizard. Ecology 58:628-635.

Dunham, A. E. 1980. An experimental study of interspecific competition between the iguanid lizards Sceloporus merriami and Urosaurus ornatus. Ecological Monographs 50:309-330.
Dunham, A. E., D. W. Tinkle, and J. W. Gibbons. 1978. Body size in island lizards: a cautionary tale. Ecology 59: $1320-1328$.

Huey, R. B., E. R. Pianka, M. E. Egan, and L. W. Coons. 1974. Ecological shifts in sympatry; Kalahari fossorial lizards (Typhlosaurus). Ecology 55:304-316.

Licht, P. 1974. Responses of Anolis lizards to food supplementation in nature. Copeia 1974(1):215-221.

Milstead, W. W. 1965. Changes in competing populations of whiptail lizards (Cnemidophorus) in southwestern Texas. American Midland Naturalist 73:75-80.

Nevo, E., C. Gorman, M. Soulé, S. Y. Yang, R. Clover, and V. Radovanovic. 1972. Competitive exclusion between insular Lacerta species (Sauria, Lacertidae). Oecologia (Berlin) 10: 183-190.

Pianka, E. R. 1967. On lizard species diversity: North American flatland deserts. Ecology 48:333-351.

- 1978. Reptilian species diversity. Pages 1-34 in C. Gans and D. W. Tinkle, editors. Biology of the Reptilia. Volume 7. Academic Press, New York, New York, USA.

Pianka, E. R., R. B. Huey, and L. R. Lawlor. 1978. Niche segregation in desert lizards. Pages 67-115 in D. J. Horn, R. Mitchell, and G. R. Stairs, editors. Analysis of ecological systems. Ohio State University Press, Columbus, Ohio, USA.

Rosenzweig, M. L. 1979. Three probable evolutionary causes for habitat selection. Pages 49-60 in G. P. Patil and M. L. Rosenzweig, editors. Contemporary quantitative ecology and ecometrics. International Co-operative Publishing House, Fairfield, Maryland, USA.

Schoener, T. W. 1975. Presence and absence of habitat shift in some widespread lizard species. Ecological Monographs 45:233-258.

- 1977. Competiton and the niche. Pages 35-136 in C. Gans and D. W. Tinkle, editors. Biology of the Reptilia. Volume 7. Academic Press, New York, New York, USA. Schroder, G. D., and M. L. Rosenzweig. 1975. Perturbation analysis of competition and overlap in habitat utilization between Dipodomys ordii and Dipodomys merriami. Oecologia (Berlin) 19:9-28.

Seber, G. A. F. 1973. The estimation of animal abundance and related parameters. Griffin, London, England.

Simon, C. A. 1975. The influence of food abundance on territory size in the iguanid lizard Sceloporus jarrovi. Ecology 56:993-998.

Smith, D. C. 1977. Interspecific competition and the demography of two lizards. Dissertation. University of Michigan, Ann Arbor, Michigan 48109 USA.

Soulé, M. 1966. Trends in the insular radiation of a lizard. American Naturalist 100:47-64.

Strong, D. R., Jr., L. A. Szyska, and D. S. Simberloff. 1979. Tests of community-wide character displacement against null hypotheses. Evolution 33:897-913.

Tinkle, D. W. 1972. The dynamics of a Utah population of Sceloporus undulatus. Herpetologica 28:351-359.

- 1981 , in press. Comparative life histories of three syntopic sceloporine lizards. Lizard ecology: studies on a model organism. Harvard University Press, Cambridge, Massachusetts, USA.

Turner, F. B., P. A. Medica, and D. D. Smith. 1974. Reproduction and survivorship of the lizard, Uta stansburiana, and the effects of winter rainfall, density and predation on these processes. United States International Biological Program Desert Biome Research Memo 74-26, Utah State University, Logan, Utah, USA. 